\title{
Metabolic modulation of chromatin: implications for DNA repair and genomic integrity
}

\author{
Jinping Liu, Jeongkyu Kim and Philipp Oberdoerffer* \\ Laboratory of Receptor Biology and Gene Expression, National Cancer Institute, National Institutes of Health, Bethesda, MD, USA
}

\section{Edited by:}

Joseph Baur, Perelman School of Medicine at the University of

Pennsylvania, USA

Reviewed by:

Sangwon F. Kim, University of

Pennsylvania, USA

Haim Cohen, Bar-llan University, Israel

Jason Locasale, Cornell University,

USA

\section{${ }^{*}$ Correspondence:}

Philipp Oberdoerffer, Laboratory of

Receptor Biology and Gene

Expression, National Cancer Institute,

National Institutes of Health, Building

41, Room B907, Bethesda, MD

20892, USA

e-mail: oberdoerfferp@mail.nih.gov
The maintenance of genomic integrity in response to DNA damage is tightly linked to controlled changes in the damage-proximal chromatin environment. Many of the chromatin modifying enzymes involved in DNA repair depend on metabolic intermediates as cofactors, suggesting that changes in cellular metabolism can have direct consequences for repair efficiency and ultimately, genome stability. Here, we discuss how metabolites may contribute to DNA double-strand break repair, and how alterations in cellular metabolism associated with both aging and tumorigenesis may affect the integrity of our genomes.

Keywords: chromatin, DNA repair, metabolism, aging, cancer

\section{INTRODUCTION}

Dynamic chromatin reorganization affects numerous cellular processes, including differentiation and development. In recent years, it has become apparent that chromatin does not only determine gene expression and epigenetic integrity of nuclear DNA, but directly contributes to the repair of genomic lesions, of which DNA double-strand breaks (DSBs) are the most toxic (Lukas et al., 2011; Shi and Oberdoerffer, 2012; Soria et al., 2012; Smeenk and van Attikum, 2013). The need for chromatin reorganization during eukaryotic DNA repair becomes apparent in light of the tight packaging of DNA in nuclear space: in humans and mice, approximately every $200 \mathrm{bp}, 146-147 \mathrm{bp}$ of DNA are wrapped around a nucleosome, which forms the structural core of the chromatin fiber. Each nucleosome consists of a histone octamer containing two molecules of $\mathrm{H} 2 \mathrm{~A}, \mathrm{H} 2 \mathrm{~B}, \mathrm{H} 3$, and $\mathrm{H} 4$, or variants thereof, assembled in one $\mathrm{H} 3-\mathrm{H} 4$ heterotetramer and two H2A-H2B heterodimers. Nucleosomes are subject to further condensation via the $\mathrm{H} 1$ linker histones, which contact the exit/entry points of the DNA strand on the nucleosome and facilitate higher order chromatin folding (Luger et al., 1997; Hansen, 2002). DNA lesions that occur in the context of chromatin must, thus, be made accessible to the repair machinery, a process that involves remodeling and/or depletion of nucleosomes as well as an array of epigenetic modifications, which can affect both DNA and histone proteins (Polo and Jackson, 2011; Smeenk and van Attikum, 2013). While the most prevalent epigenetic alterations of DNA are methyl-based modifications of cytosines in CpG context, histones are subject to a wide range of reversible, post-transcriptional modifications including acetylation, methylation, phosphorylation, ubiquitylation, sumoylation, and ADP ribosylation (Kouzarides, 2007). Over the past decade, all of these modifications have been implicated in the modulation of DSB repair
(Lukas et al., 2011; Shi and Oberdoerffer, 2012; Soria et al., 2012; Smeenk and van Attikum, 2013).

Many of the enzymes responsible for the deposition or removal of chromatin modifications require metabolic intermediates as cofactors or substrates for their activity. Changes in metabolism and, consequently, metabolite availability are tightly associated with both aging and cancer (Ward and Thompson, 2012; Cosentino and Mostoslavsky, 2013), raising the intriguing possibility that age- or disease-associated metabolic alterations can result in the deregulation of DNA repair by altering chromatin function. In the following, we will highlight the impact of metabolites on chromatin modifiers involved in DSB repair and speculate how changes in metabolite abundance may influence genome maintenance and nuclear integrity.

\section{METABOLITES AS MEDIATORS OF CHROMATIN CHANGES}

Metabolic programs coordinate energy intake and its use to control cell survival and growth. Eukaryotic cells rely on oxidative metabolism as the most efficient way to produce energy from nutrients. The mitochondrial tricarboxyclic acid (TCA) cycle oxidizes pyruvate derived from glucose or fatty acids to $\mathrm{CO}_{2}$, thereby generating adenosine triphosphate (ATP) and the reduced form of the redox cofactors nicotinamide adenine dinucleotide (NADH) and flavin adenine dinucleotide $\left(\mathrm{FADH}_{2}\right)$. Oxidation of NADH and $\mathrm{FADH}_{2}$ to $\mathrm{NAD}^{+}$and $\mathrm{FAD}$, in turn, promotes the production of ATP via oxidative phosphorylation and the electron transport chain (ETC). ATP and NADH can also be generated from glucose directly via glycolysis. For a detailed description of these metabolic pathways, we refer the reader to a comprehensive review by Locasale and Cantley (2011). In addition to energy production, cellular metabolism ensures the balanced generation of intermediate metabolites, which are required for cell growth and/or serve 
as co-enzymes or substrates for a number of enzymatic processes (Yuan et al., 2013). The latter is particularly relevant during conditions of nutrient excess, when cells were found to switch to what is known as aerobic glycolysis to maintain growth. The same metabolic switch is also observed in many cancer cells, where it was first described by Otto Warburg and is, thus, referred to as Warburg effect (Warburg, 1956; Ward and Thompson, 2012).

Accumulating evidence suggests that metabolic changes associated with age and/or tumor development may not simply be a consequence of the latter. This notion has been discussed in a number of number of recent reviews, which implicate altered metabolite profiles both in the regulation of p53 activity (Vousden and Ryan, 2009) and the epigenetic control of gene expression in aging and disease (Vousden and Ryan, 2009; Ward and Thompson, 2012; Yun et al., 2012; Cosentino and Mostoslavsky, 2013). Here, we propose that metabolite-associated changes in chromatin may further contribute to aging and malignant transformation through the deregulation of DNA repair. We focus on chromatin modifications that have been extensively investigated in the context of DNA DSB repair and highlight the key metabolite cofactors and/or substrates required for these modifications: specifically we discuss (i) acetyl-CoA-dependent acetylation and $\mathrm{NAD}^{+}$-dependent deacetylation of histones, (ii) $\mathrm{NAD}^{+}$-dependent poly-ADP ribosylation, and (iii) $S$-adenosylL-methionine (SAM)-dependent methylation as well as FAD $/ \alpha$ ketoglutarate-dependent demethylation of histones and/or DNA (see Figure 1A).

\section{HISTONE (DE)ACETYLATION}

The acetylation of histones increases the negative charge of chromatin fibers, which renders chromatin structurally accessible and is, therefore, generally associated with less densely packed chromatin (euchromatin) and concomitant active gene transcription (Kouzarides, 2007). Acetylation of a specific histone residue (H3K56) has further been linked to the (re-)assembly of nucleosomes following replication or DNA repair (Downs, 2008; Das et al., 2009), and a similar process has been described for H3K4 acetylation during the re-assembly of densely packed, heterochromatic DNA (Xhemalce and Kouzarides, 2010). Histone acetylation requires the acetyl-group donor acetyl-CoA. In mammalian cells, nuclear acetyl-CoA is generated from glucose that has been converted to citrate via the TCA cycle. Unlike acetyl-CoA, citrate can cross the mitochondrial membrane and serves as substrate for ATP-citrate lyase (ACL), which is localized in the cytoplasm

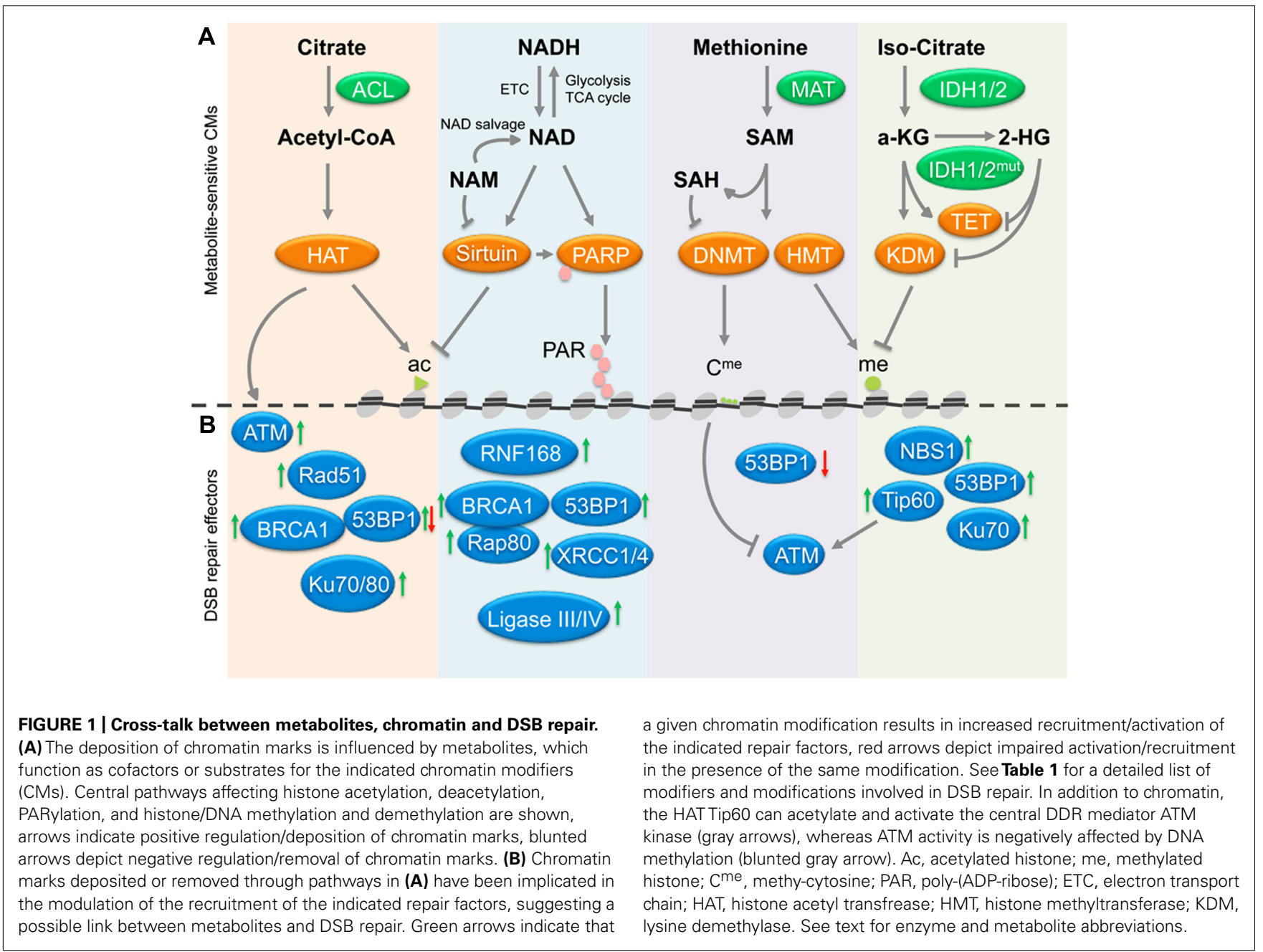


and nucleus and is essential for non-mitochondrial acetyl-CoA production (Bauer etal., 2005). Changes in glucose availability or ACL levels are, thus, expected to have a direct impact on acetyl-CoA-dependent nuclear acetylation reactions. Indeed, Thompson and colleagues demonstrated that depletion of ACL results in reduced histone acetylation and concomitant gene silencing, whereas growth factor signaling as well as increased glucose metabolism resulted in excess acetyl-CoA production, increased acetyl-histone levels and increased gene expression (Wellen et al., 2009).

Like the acetylation of histones, their deacetylation can be modulated by metabolite availability. Perhaps the most prominent example are sirtuins, or class III histone deacetylases (HDACs), which depend on the oxidized form of $\mathrm{NADH}, \mathrm{NAD}^{+}$, as a co-factor. Both overall $\mathrm{NAD}^{+}$abundance and the cellular ratio of $\mathrm{NAD}^{+} / \mathrm{NADH}$ are, therefore, critical determinants of sirtuin activity (Imai et al., 2000; Lin et al., 2002). Notably, sirtuin-dependent deacetylation converts its co-factor $\mathrm{NAD}^{+}$to nicotinamide (NAM), a vitamin B3 precursor that functions as a non-competitive sirtuin inhibitor (Bitterman et al., 2002). NAM can be recycled to $\mathrm{NAD}^{+}$via NAD salvage pathways, and the enzymes involved in this pathway were found to promote sirtuin activity in yeast and mammalian cells (Anderson et al., 2003; Yang et al., 2007). Although sirtuin function has been linked to numerous cellular processes, their impact on chromatin reorganization is emphasized by reports demonstrating sirtuin-dependent gene repression as well as maintenance of repressive chromatin structures, including telomeric and centromeric DNA (Vaquero et al., 2004, 2007; Michishita et al., 2008, 2009; Oberdoerffer et al., 2008; Yang et al., 2009; Haigis and Sinclair, 2010; Palacios et al., 2010).

Taken together, these findings indicate that both nutrient excess and aberrant cell growth may favor an overall increase in histone acetylation and active transcription, by increasing acetyl-CoA production and simultaneously inhibiting $\mathrm{NAD}^{+}$-dependent histone deacetylation.

\section{POLY-(ADP-RIBOSYL)ATION}

In addition to sirtuins, $\mathrm{NAD}^{+}$is also a co-factor for poly-(ADPribose) polymerases (PARPs), a family of enzymes that plays an important role in the regulation of chromatin packaging, transcription, DNA replication, and DNA repair. PARPs utilize $\mathrm{NAD}^{+}$to transfer ADP-ribose to histones, non-histone proteins, and PARP itself. The poly-(ADP-ribosyl)ation (PARylation) of non-histone proteins has been implicated in numerous cellular processes ranging from transcription to intracellular trafficking to cell division and has been comprehensively discussed elsewhere (Schreiber et al., 2006; Beneke, 2012). Perhaps most relevant for this review, PARP proteins have been directly linked to chromatin (re)organization in response to a variety of developmental or environmental cues, such as steroids, heat shock, or genotoxic stress. PARP activation results in the evolutionarily conserved, PARdependent stripping of chromatin proteins from DNA, thereby promoting chromatin opening and concomitant transcriptional activation (Tulin and Spradling, 2003; Martinez-Zamudio and $\mathrm{Ha}$, 2012). Moreover, PARP1 promotes the exclusion of the linker histone $\mathrm{H} 1$ at transcription start sites and is required to maintain promoter-associated active chromatin marks (Krishnakumar and
Kraus, 2010). Conversely, inhibition of PARP activity was found to cause an increase in the number and density of heterochromatin foci as well as DNA methylation (de Capoa et al., 1999), which may at least in part be due to PAR-mediated inhibition of DNA methyltransferase 1 (DNMT1; Reale et al., 2005). Like most posttranslational modifications, PARylation is a reversible process. The hydrolysis of PAR chains is catalyzed by poly-ADP ribose glycohydrolase, which does not require additional metabolite cofactors and will, thus, not further be discussed (Feng and Koh, 2013).

\section{HISTONE AND DNA (DE)METHYLATION}

In contrast to acetylation and PARylation, both DNA and histone methylation are frequently associated with the establishment and/or maintenance of repressive chromatin domains. Densely packed chromatin, or heterochromatin, which is largely inaccessible to the transcription machinery, is highly CpG methylated and harbors characteristic methyl-histone marks, such as $\mathrm{H} 3 \mathrm{~K} 9 \mathrm{me} 3$ (constitutive heterochromatin) or H3K27me3 (facultative heterochromatin). Notably, histone methylation can also be associated with active transcription, as is the case for promoter associated H3K4 trimethylation and co-transcriptionally deposited H3K36 trimethylation. For a comprehensive overview of the occurrence and function of DNA and histone methylation, we refer the reader to recent reviews (Cedar and Bergman, 2009; Black et al., 2012).

Both DNA and histone methyltransferase enzymes (DNMTs and HMTs) rely on SAM as a common co-substrate for methyl group transfers. SAM is generated by adding ATP to methionine via methionine adenosyltransferase (MAT). As a result of the methyl transfer reaction, SAM is converted to S-adenosyl homocysteine (SAH), which is a potent inhibitor of both HMT and DNMT activity. SAH can be cleared by hydrolysis to adenosine and homocysteine. Methylation of DNA and histones is thus sensitive to cellular SAH, SAM, and homocysteine levels (reviewed in Grillo and Colombatto, 2008; Yun et al., 2012). Notably, in addition to being restored to methionine and eventually SAM, homocysteine can serve as a precursor for glutathione (GSH) synthesis. The latter serves as a major cellular redox buffer in response to oxidative stress, which in turn is tightly linked to both cancer and aging (Haigis and Yankner, 2010). Depletion of GSH due to increased reactive oxygen species (ROS) can divert homocysteine away from the methionine recycling pathway, which may, in turn, result in a decrease in SAM and inhibition of methyltransferase activity (Yun et al., 2012).

Although methylation was long considered to be an irreversible epigenetic mark, several enzymes that allow for the conversion and/or removal of methyl groups from DNA and histones have been uncovered in recent years. The first demethylase to be discovered was LSD1, a lysine demethylase, which specifically removes methyl groups from mono- and dimethylated H3K4 (Shi et al., 2004). The LSD1-mediated demethylation reaction requires FAD as a cofactor, which is reduced to FADH2 during the amine oxidation of N-methylated lysine substrates, providing a link between energy consumption and LSD1 activity (Shi et al., 2004; Forneris et al., 2005).

In addition to LSD1, a second, larger family of Jumonji C (JmjC) domain containing histone demethylases has been identified, which harbors $\alpha$-ketoglutarate $(\alpha-K G)$-dependent 
dioxygenase activity (Black et al., 2012). $\alpha-\mathrm{KG}$ is a TCA cycle intermediate that is generated from isocitrate by isocitrate dehydrogenases (IDH) 1 (cytosolic) and 2 (mitochondrial; Ward et al., 2010). Notably, $\alpha-K G$ levels do not only affect histone demethylases, but also the recently discovered TET family of 5-methylcytosine hydroxylases, which are involved in the demethylation of DNA (Kriaucionis and Heintz, 2009; Tahiliani et al., 2009; Ward and Thompson, 2012). The function of both TET and JmjC enzymes is directly affected by several recurrent somatic mutations of IDH1 and IDH2, which are commonly found in glioma (75\%; Parsons et al., 2008) and acute myeloid leukemia (20\%; Mardis et al., 2009). These mutations result in aberrant enzyme activity, which converts $\alpha$-KG to 2-hydroxy-ketoglutarate (2-HG; Yang et al., 2012). 2-HG is a competitive inhibitor of $\alpha$-KG-dependent enzymatic reactions (Xu et al., 2011), which in turn leads to genome-wide alterations in both histone and DNA methylation (Xu et al., 2011; Lu et al., 2012).

Together, these observations underline the power of metabolic changes with regard to epigenetic maintenance, be it in response to altered growth conditions and/or nutrient availability, or due to mutations in key metabolic enzymes. In the following we will discuss the possibility that altered metabolite profiles may, at least in part, contribute to age-related genome instability and malignant transformation by altering the regulation of DNA repair through chromatin.

\section{METABOLITE-SENSITIVE ASPECTS OF CHROMATIN-DIRECTED DSB REPAIR}

Double-strand breaks are incompatible with DNA replication and thus represent one of the most toxic DNA lesions. To eliminate DSBs, eukaryotic cells generally employ one of two repair pathways: non-homologous end-joining (NHEJ) or homologous recombination (HR). HR allows for the error-free repair of a DSB in the presence of a homologous, undamaged DNA template, usually the sister chromatid, and is typically restricted to $S$ and G2 phases of the cell cycle. To allow for invasion of the undamaged template, the recombination event requires the generation of single-stranded DNA (ssDNA) via the resection of broken DNA ends. NHEJ, on the other hand, involves the religation of the broken ends with no or minimal resection of DNA ends and can occur in all phases of the cell cycle. In case of minimal end resection, the lack of template, however, bears the risk of mutations upon repair (see Ciccia and Elledge, 2010; Polo and Jackson, 2011; Chapman et al., 2012) for recent, comprehensive reviews).

Over the past decade, it has become evident that chromatin modifications play a critical role in most if not all phases of NHEJ and HR. A common theme to both repair pathways is the need to make chromatin accessible for repair factors (Lukas et al., 2011; Soria et al., 2012; Smeenk and van Attikum, 2013). This process involves the remodeling, depletion, and re-assembly of nucleosomes, the acetylation of histones as well as the incorporation of histone variants associated with active chromatin, such as H2AZ (Murr et al., 2006; Xu et al., 2012; Smeenk and van Attikum, 2013). In addition, numerous histone modifications have been shown to function as assembly platforms for repair factors through direct interaction of these proteins with the modified histone. Perhaps the most prominent such modification is the phosphorylation of $\mathrm{H} 2 \mathrm{AX}$ on serine 139 (referred to as $\gamma-\mathrm{H} 2 \mathrm{AX}$ ), which is mediated by
PI3 kinase like linase (PIKK) family members ATM, ATR, or DNAPKcs. $\gamma$-H2AX provides a high affinity binding site for MDC1, which in turn orchestrates the recruitment of a variety of functionally distinct effector proteins, such as 53BP1 and BRCA1, two central mediators of NHEJ and HR, respectively (Bekker-Jensen and Mailand, 2010). In addition to histone modifications common to most if not all repair pathways, such as $\gamma-\mathrm{H} 2 \mathrm{AX}$, recent evidence has identified a growing list of more selective modifications, which can help fine-tune or even determine the choice of repair factors, and thus the repair pathways involved in the resolution of the break (reviewed in Lukas et al., 2011; Shi and Oberdoerffer, 2012; Soria et al., 2012; Smeenk and van Attikum, 2013). In the following we will focus on the metabolite-sensitive chromatin modifications described above and discuss their impact on DSB repair and genomic integrity (see Figure 1B and Table 1).

\section{ACETYL-CoA AND DSB-ASSOCIATED HISTONE ACETYLATION}

Acetyl-CoA-dependent histone acetylation is a central aspect of the DNA damage response, as it facilitates the relaxation of DSBsurrounding chromatin and concomitant repair factor access. Perhaps the most prominent DSB repair-associated histone acetyltransferase (HAT) is Tip60 (or KAT5). Tip60 is rapidly recruited to sites of DNA damage in a manner that is dependent on the break-sensing Mre11-Rad50-Nbs1 (MRN) complex, and promotes acetylation of DSB-surrounding histone H4 (Murr et al., 2006) as well as the DDR mediator ATM (Sun et al., 2005). The latter was found to amplify ATM activity and is essential for the DSB-induced, ATM-dependent checkpoint response (Sun et al., 2007). Similarly, Tip60-mediated acetylation of histone H4 was found to promote the recruitment of several repair factors central to both HR and NHEJ, including BRCA1, Rad51, and 53BP1 (Murr et al., 2006), suggesting a synergistic effect of Tip60-induced ATM and $\mathrm{H} 4$ acetylation. Notably, recent evidence suggests that H4K16 acetylation by Tip60 can selectively interfere with the recruitment of 53BP1, thereby promoting BRCA1 recruitment (Hsiao and Mizzen, 2013; Tang et al., 2013). Moreover, depletion of both Tip60 and its co-factor TRRAP have been shown to inhibit DNA repair by HR, although decreased histone acetylation was also shown to impair NHEJ (Murr et al., 2006; Hsiao and Mizzen, 2013; Tang et al., 2013), suggesting a complex and likely dynamic role for acetylation and deacetylation in the regulation of DNA repair that warrants further investigation.

Several additional HATs have been linked to DSB-associated chromatin remodeling over the past years. GCN5 (or KAT2A) links the dynamic acetylation and deacetylation of several residues on H3 and H4 to HR in yeast (Tamburini and Tyler, 2005). Notably, induction of DSBs in mammalian cells has been linked to a transient reduction in $\mathrm{H} 3 \mathrm{~K} 9 \mathrm{ac}$ as well as $\mathrm{H} 3 \mathrm{~K} 56 \mathrm{ac}$, and GCN5 was identified as a HAT responsible for re-establishing the latter mark (Tjeertes et al., 2009). In addition to GCN5, CREB-binding protein (CBP)/P300 has been shown to promote the acetylation of H3K56 in response to DNA damage or replication stress. Histones bearing acetylated K56 are, in turn, (re-)assembled into chromatin in yeast, flies, and human cells, forming foci that colocalize with sites of DNA repair (Das et al., 2009). Depletion of CBP/P300 reduced recruitment of the end-joining factors $\mathrm{Ku} 70 / 80$ and, consequently, NHEJ efficiency, supporting a functional link between nucleosome 
Table 1 | Metabolite-sensitive chromatin modifiers involved in DSB repair.

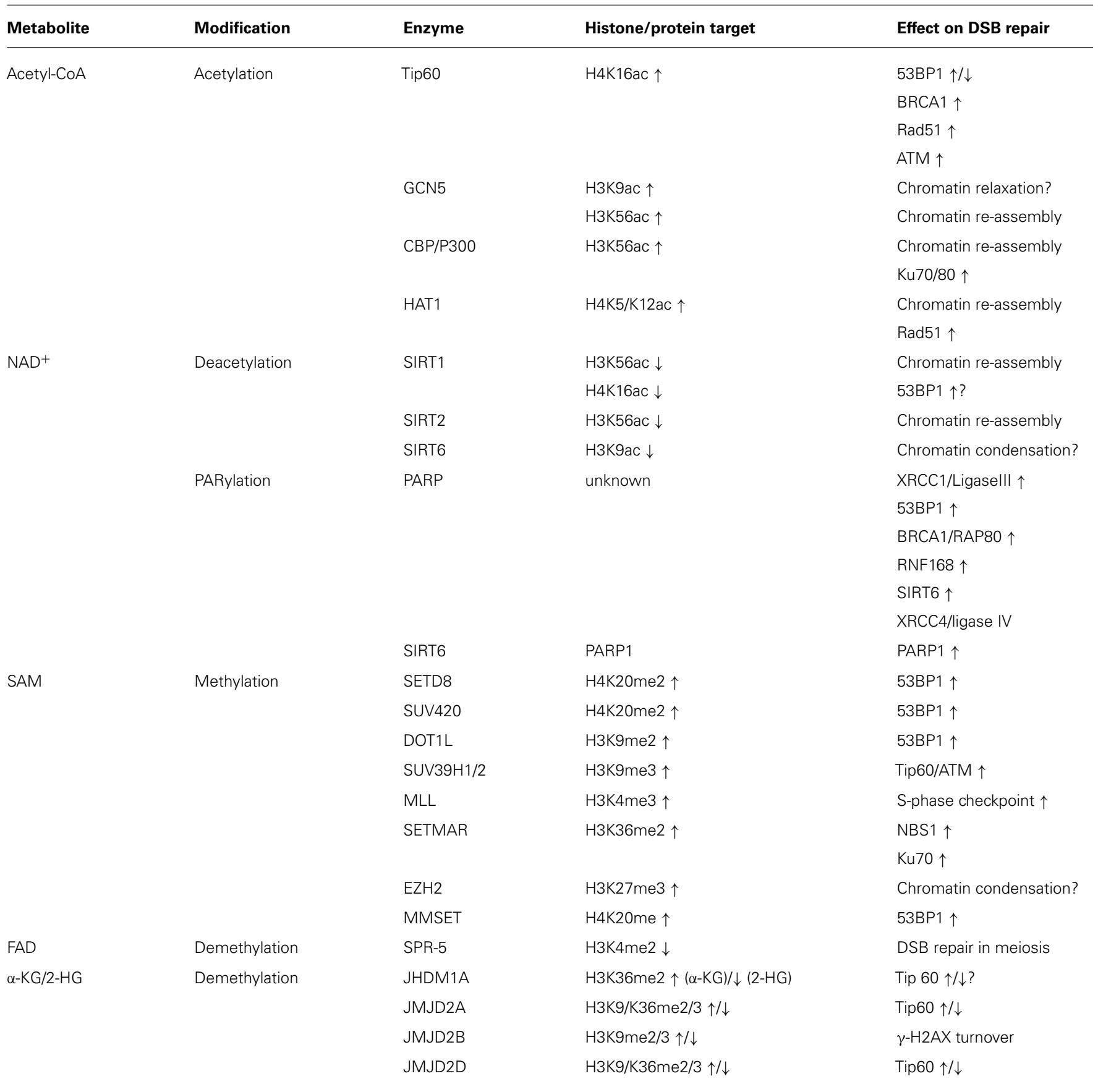

turnover and repair by NHEJ (Ogiwara et al., 2011). Similar to the role of H3K56ac, HAT1-mediated K5/K12 acetylation of newly synthesized $\mathrm{H} 4$ is required for their efficient incorporation into DSB-proximal chromatin. However, HAT1 depletion has been linked to defects in HR rather than NHEJ due to impaired recruitment of the ssDNA binding protein Rad51 (Yang et al., 2013). Interestingly, in addition to and likely preceding HAT-mediated chromatin re-assembly, increased acetylation of several of the core histones was found to promote their polyubiquitin-independent degradation in response to DNA damage. The resulting chromatin disassembly is thought to facilitate repair factor access and involves the proteasome activator PA200, which binds to acetylated histones (Qian et al., 2013). Notably, both DNA damage and aging have recently been shown to promote histone loss, suggesting a mechanistic link between the two processes, possibly through a common increase in chromatin decondensation (Feser et al., 2010; O'Sullivan et al., 2010). Increased histone acetylation, in turn, was found to activate ATM in the absence of DNA breaks, indicative of a positive feedback that may eventually result in deregulated DDR, genomic instability, and/or cell cycle arrest observed with age (Bakkenist and Kastan, 2003; Kaidi and Jackson, 2013). 
Together, these findings demonstrate that the modulation of histone acetylation has a significant, yet complex impact on the DDR and can affect repair via both NHEJ and HR. It will be of interest to determine how changes in the essential HAT co-factor acetyl-CoA, and by extension glucose availability, affect DSB repair and genomic stability in the context of either excessive growth (tumorigenesis) or growth arrest (senescence).

\section{NAD+-DEPENDENT HISTONE DEACETYLATION AND PARylation IN DSB REPAIR}

Double-strand break-associated histone acetylation is a dynamic process that is counteracted by HDACs, which can be sensitive to metabolite availability as is the case for $\mathrm{NAD}^{+}$-dependent sirtuins [see Histone (de)acetylation]. To date, at least three of the four nuclear mammalian sirtuins, SIRT1, SIRT2, and SIRT6 have been implicated in DNA damage control (Haigis and Sinclair, 2010). However, although these proteins have been reported to affect both HR and NHEJ by deacetylating non-histone DNA repair proteins, evidence for sirtuin-mediated histone deacetylation at sites of DSBs is largely circumstantial. Both SIRT1 and SIRT6 are recruited to sites of DNA damage (Oberdoerffer et al., 2008; Kaidi et al., 2010; Toiber et al., 2013) and SIRT6 was recently found to mediate DSB-specific H3K56 deacetylation (Toiber et al., 2013). Notably, recruitment of SIRT6 to DSB-flanking chromatin may help activate its deacetylase activity, as the latter was found to require interaction with intact nucleosomes (Gil et al., 2013). In addition to $\mathrm{H} 3 \mathrm{~K} 56 \mathrm{ac}$ deacetylation, SIRT6 promotes the recruitment of the SNF2H remodeling factor and concomitant chromatin accessibility at sites of damage. If these processes are functionally linked remains to be determined (Toiber et al., 2013). Similar to SIRT6, SIRT1 and SIRT2 are able to deacetylate H3K56ac, which was found to modulate CBP/P300-dependent H3K56 acetylation and concomitant chromatin re-assembly at DNA breaks (Das et al., 2009). In addition, SIRT1 was shown to deacetylate H4K16ac, which may in turn counteract Tip60 activity and, thus, alter ATM activation as well as the recruitment of DSB repair factors (Vaquero et al., 2004; Tang etal., 2013). Finally, SIRT6 and to a lesser extent SIRT1 can deacetylate $\mathrm{H} 3 \mathrm{~K} 9 \mathrm{ac}$, which may have implications for the modulation of DSB-induced chromatin accessibility (Vaquero et al., 2004). However, evidence for sirtuin-dependent, DSB-specific deacetylation of many of these marks is missing. Future work is expected to provide a better understanding of how sirtuins may modulate the DDR via targeted histone deacetylation.

While the role of sirtuins in DSB-associated chromatin reorganization is only emerging, the $\mathrm{NAD}^{+}$-dependent PARP enzymes PARP1 and PARP2 are well-established modulators of DSBproximal chromatin accessibility and, consequently, DSB repair. PARP activation is one of the first events in the DDR, which results in extensive PARylation in the vicinity of DSBs and facilitates the recruitment of early repair sensors such as Mre11 (Schreiber et al., 2006; Yelamos et al., 2011). Deletion of PARP1 and PARP2 results in increased DNA damage sensitivity, increased genomic instability and, in case of PARP1, increased tumor formation (Menissier de Murcia et al., 2003; Tong et al., 2007). PARP1 has been found to interact with the NHEJ factors XRCC1 and ligase III and is required for NHEJ under conditions that involve minimal end resection (known as alternative NHEJ; Audebert et al., 2004). Notably, the latter is inhibited by $53 \mathrm{BP} 1$, suggesting that PARP1 may counteract 53BP1 recruitment (Bouwman et al., 2010; Bunting et al., 2010; Chapman et al., 2012). Consistent with this notion, PARP1 was recently shown to promote $\mathrm{HR}$ by regulating chromatin expansion and spatial accumulation of the BRCA1/RAP18 complex at DSBs (Smeenk et al., 2013). Interestingly, the DDR-relevant target(s) for PARylation remain to be identified, and although PARylation of histone tails has been reported (Messner et al., 2010), it is unclear whether these modifications affect DSB repair. Notably, SIRT6 was recently found to alter DSB repair by mono-ribosylating and, thus, activating PARP1. SIRT6-dependent activation of PARP is dependent on oxidative stress, suggesting that $\mathrm{NAD}^{+}$-dependent repair factors may help integrate DNA repair and stress signaling pathways (Mao et al., 2011).

Together, these findings indicate that, similar to acetyl-CoA, alterations in cellular $\mathrm{NAD}^{+}$levels can modulate DSB repair. Consistent with the opposing activities of HATs and HDACs in the DDR, acetyl-CoA is associated with nutrient excess, whereas $\mathrm{NAD}^{+}$is elevated under conditions of nutrient deprivation. Notably, PARylation and histone deacetylation appear to have similarly opposing effects on chromatin packaging, yet both PARPs and sirtuins depend on $\mathrm{NAD}^{+}$. It will, thus, be of particular interest to determine if and how PARylation and sirtuin-mediated histone deacetylation cooperate in a scenario where $\mathrm{NAD}^{+}$is limiting, as observed both with age and in highly glycolytic tumor cells (Elstrom et al., 2004; Braidy et al., 2011; Massudi et al., 2012). Interestingly, PARP can negatively regulate SIRT1 expression, underlining the functional crosstalk between the two enzymatic processes (Bai et al., 2011a,b). Consistent with an overall genomeprotective role for $\mathrm{NAD}^{+}$, high levels of $\mathrm{NAD}^{+}$were recently reported to correlate with radio-protection in human glioma cells (Sahm et al., 2013), whereas low level NAD ${ }^{+}$were associated with increased DSB damage in aged cells (Braidy et al., 2011).

\section{SAM AND DSB-ASSOCIATED HISTONE METHYLATION}

Like PARylation and histone acetylation, their methylation is emerging to be an integral aspect of the cellular response to DSBs. And like all acetylation reactions are dependent on acetyl-CoA, all methyl-group additions require a single intermediate metabolite, SAM, as essential co-factor, making both processes intricately linked to nutrient availability and cell growth. However, while acetylation is often thought of as a means to change DSB-proximal chromatin structure and accessibility, methylation of histones appears to be a more selective modulator of repair factor recruitment (van Attikum and Gasser, 2009; Bekker-Jensen and Mailand, 2010; Shi and Oberdoerffer, 2012). Perhaps the most prominent example for the latter is the NHEJ-associated repair factor 53BP1, the recruitment of which to DSBs depends on the binding of a subset of dimethylated histone lysine residues via its conserved tandem tudor domains (Huyen et al., 2004; Botuyan et al., 2006). Both 53BP1 and its yeast ortholog Crb2 show strong affinity for dimethylated H4K20 compared with unmethylated or trimethylated H4K20 (Botuyan et al., 2006). H4K20 methylation appears to be established prior to DNA damage and involves the HMTs SETD8 and SUV420 (Hsiao and Mizzen, 2013), although DSBinduced H4K20 dimethylation via MMSET has also been reported (Pei et al., 2011). In addition to H4K20, H3K79 was found to 
interact with 53BP1 when dimethylated by DOT1L, albeit with weaker affinity (Huyen et al., 2004; Botuyan et al., 2006). Underlining the requirement for dimethyl-histone binding, deletion of the HMTs responsible for either H4K20me2 or H3K79me2 resulted in impaired formation of $53 \mathrm{BP} 1$ foci in response to DNA damage and concomitant DNA repair defects (Huyen et al., 2004; Wakeman et al., 2012; Hsiao and Mizzen, 2013). Similar to H4K20me2, H3K79me2 appears to be established prior to DNA damage rather than being induced by the DDR (Huyen et al., 2004), raising the intriguing question of how pre-existing, DNA damage-independent histone marks can elicit a DSB-specific damage response. This conundrum was addressed recently, when Durocher and colleagues demonstrated that 53BP1 recruitment requires the ubiquitination of $\mathrm{H} 2 \mathrm{~A}-\mathrm{K} 15$ as a DSB-induced, additional histone modification for optimal binding to H4K20me2 containing nucleosomes. H2A-K15 ubiquitination is dependent on RNF168, an E3 ligase that is recruited to chromatin following DSB induction (Fradet-Turcotte et al., 2013). Notably, 53BP1 binding to H4K20 dimethylated nucleosomes can also be negatively regulated via acetylation of K16 on the same H4 tail (Tang et al., 2013).

Evidence for the involvement of additional, pre-existing histone methyl marks in the DDR is rapidly accumulating. Both H3K9 and $\mathrm{H} 3 \mathrm{~K} 36$ trimethylation were shown to activate the HAT activity of DSB-associated Tip60 (Sun et al., 2009). Indeed, the direct interaction of Tip 60 with $\mathrm{H} 3 \mathrm{~K} 9 \mathrm{me} 3$ at DSBs was found to be essential for Tip60-mediated activation of ATM and the downstream DDR effectors. Consequently, deletion of the enzymes responsible for H3K9 trimethylation, SUV39H1, and SUV39H2, abolished Tip60 HAT activity in response to DSB induction (Sun etal., 2009). DSB-induced structural changes in break-proximal chromatin have been implicated in the exposure of these trimethylated histone marks, and remarkably, experimentally induced chromatin perturbation can elicit activation of Tip60/ATM without the induction of DSBs (Bakkenist and Kastan, 2003; Kaidi and Jackson, 2013).

In addition to pre-existing methyl marks, a number of DSBinduced changes in histone methylation have now been linked to DSB repair: the mixed-lineage leukemia histone methyltransferase MLL was found to activate the S-phase checkpoint in response to DSBs via trimethylation of H3K4 (Liu et al., 2010), although the mechanistic basis for this phenomenon remains to be investigated. SETMAR/Metnase was found to mediate dimethylation of $\mathrm{H} 3 \mathrm{~K} 36$ at DSBs, which appears to promote NHEJ via the recruitment of Nijmegen breakage syndrome 1 (NBS1) and Ku70 to DSB sites via a yet to be determined pathway (Fnu et al., 2011). Finally, the polycomb-associated H3K27 HMT EZH2 is recruited to DSBs, coinciding with rapid but transient $\mathrm{H} 3 \mathrm{~K} 27$ trimethylation. Notably, this process appears to be independent of PIKK signaling but requires PARP activity. Although its functional implications for the DDR remain to be investigated, depletion of EZH2 renders cells sensitive to ionizing radiation (IR; Chou et al., 2010).

Together, these findings suggest that changes in both steady state and DSB-induced histone methylation can affect the induction and/or execution of the DDR, which is in turn directly affected by SAM availability. Notably, the latter is negatively affected by oxidative stress, which competes for the SAM-precursor homocysteine due to GSH depletion [see Histone and DNA (De)methylation]. Oxidative stress is frequently observed in both aged and tumor cells, suggesting that histone methylation-dependent aspects of the DDR may be impaired under these conditions.

\section{FAD-, $\alpha$-KG-, AND DSB-ASSOCIATED HISTONE DEMETHYLATION}

Since the discovery of the first histone demethylase, LSD1, demethylases have been identified for many of the known methylated histone residues (Black et al., 2012). LSD1 and the closely related LSD2 are unique in that they required FAD as a cofactor, whereas JmjC domain containing dioxygenases, the largest class of histone lysine demethylases, require $\alpha-K G$. Given this distinction, LSD1 and JmjC demethylases have the potential to respond differently to nutrient availability, which in turn may have consequences for the metabolic regulation of DSB repair.

The C. elegans LSD1 otholog SPR-5, which demethylates $\mathrm{H} 3 \mathrm{~K} 4 \mathrm{me} 2$ was shown to mediate DSB repair in meiosis (Nottke et al., 2011). However, a direct role for LSD1/LSD2 in the DDR in mammalian cells remains to be identified. In contrast, several JmjC-type demethylases have been directly linked to DSB repair. JHDM1A (KDM2A) mediated demethylation of H3K36me2 at DSBs was found to counteract SETMAR-mediated H3K36 dimethylation, and concomitantly, repair via NHEJ (Fnu et al., 2011). Recently, JMJD2B (KDM4B) was found to promote demethylation of $\mathrm{H} 3 \mathrm{~K} 9 \mathrm{me} 2$ and $\mathrm{H} 3 \mathrm{~K} 9 \mathrm{me} 3$ in response to DNA damage and KDM4B depletion resulted in accelerated resolution of DNA breaks as indicated by reduced frequency of $\gamma-\mathrm{H} 2 \mathrm{AX}$ foci late in the DDR (Young et al., 2013). In addition, the closely related KDM4 demethylases JMJD2A (KDM4A) and JMJD2D (KDM4D), which mediate demethylation of trimethylated $\mathrm{H} 3 \mathrm{~K} 9 / \mathrm{H} 3 \mathrm{~K} 36$ or H3K9, respectively (Klose et al., 2006; Whetstine et al., 2006), were shown to interfere with the activation of Tip60 by reducing its binding to DSB-proximal chromatin (Sun et al., 2009). Notably, KDM4A can bind to methylated H4K20 and is degraded following DNA damage, thereby allowing for the accumulation of 53BP1 at DSBs. It is, however, unclear if this process involves demethylation of methyl-H4K20 (Mallette et al., 2012).

Together, these findings suggest that the negative regulation of DNA damage signaling is a common feature of KDM function in DNA repair, whereas inhibition of KDM activity may result in increased DDR activation. It is, therefore, tempting to speculate that the JmjC-type KDM inhibitor 2-HG, which is the product of a tumor-associated gain of function mutation in IDH genes [see Histone and DNA (De)methylation], may alter repair efficiency in tumor cells. Overexpression of IDH mutant enzymes as well as administration of 2-HG have been shown to promote an increase in several histone methyl marks associated with DSB repair, including $\mathrm{H} 3 \mathrm{~K} 9 \mathrm{me} 3, \mathrm{H} 3 \mathrm{~K} 27 \mathrm{me} 3$, and $\mathrm{H} 3 \mathrm{~K} 4 \mathrm{me} 3$ and, to a lesser extent H3K36me3 and H3K79me2 (Lu et al., 2012). Increased H3K9me3 abundance may activate Tip60, and consequently ATM-mediated damage signaling. Similarly, increased H3K79 methylation may promote the recruitment of 53BP1. Notably, the latter has been shown to interfere with $\mathrm{HR}$ in the absence of BRCA1, thereby accounting for genomic instability observed in BRCA1 mutant tumors (Bouwman et al., 2010; Bunting et al., 2010). Together, 
these findings suggest that interference with histone demethylation may contribute to aberrant DDR activation and/or altered repair outcome, which may eventually contribute to genomic instability and, thus be exploited for genotoxic cancer therapy.

\section{DNA METHYLATION AND DEMETHYLATION AT DSBs}

Like the methylation of a variety of histone residues, DNA methylation was found to accumulate at sites of DSBs (Cuozzo et al., 2007). This process appears to require the maintenance methyltransferase DNMT1, which is rapidly and transiently recruited to DSB. DNMT1 recruitment is dependent on its ability to interact with both the DNA polymerase processivity factor PCNA and ATR, suggesting a role in DSB repair during DNA replication in S phase. Notably, reduced DNMT1 activity results in aberrant activation of the DDR in the absence of damage (Ha et al., 2011). Consistent with DNMT1 being a suppressor of abnormal DDR activation, deletion of DNMT1 in cancer cells was found to result in cell cycle arrest in G2/M and mitotic catastrophy in escapes (Chen et al., 2007). Like DNMT1, the DNMT1-associated protein 1 (DMAP1) was found to link DSB-associated DNA methylation to DSB repair. DMAP1 is selectively enriched in DSB-flanking chromatin and DMAP1 depletion can cause (persisting) hypomethylation, suggesting that DMAP1 activates DNMT1 preferentially at sites of DNA damage. Notably, DMAP1 depletion resulted in enhanced $\mathrm{HR}$, which further supports a repressive role for methylation in this process (Lee et al., 2010). DMAP1 was also found to associate with the TIP60/P400 HAT complex, and appears to be required for Tip60-mediated H4K16 acetylation and concomitant ATM activation. Consistent with the latter, DMAP1 depletion caused increased IR sensitivity and a decrease in 53BP1 foci formation (Murr et al., 2006; Penicud and Behrens, 2013). It will be interesting to determine if DMAP1-dependent ATM activation involves DNA methylation via DNMT1. Given the inhibitory effect on HR and 53BP1 recruitment, it is further tempting to speculate that DNA methylation and DMAP1 can serve as a modulator of repair pathway choice.

In contrast to DNA methylation, evidence for DSB-associated DNA demethylation is missing. Perhaps to most promising candidates for the latter are the TET family of proteins, however, a role for TET proteins in DSB repair remains to be identified.

\section{REFERENCES}

Anderson, R. M., Bitterman, K. J., Wood, J. G., Medvedik, O., and Sinclair, D. A. (2003). Nicotinamide and PNC1 govern lifespan extension by calorie restriction in Saccharomyces cerevisiae. Nature 423, 181-185. doi: $10.1038 /$ nature 01578

Audebert, M., Salles, B., and Calsou, P. (2004). Involvement of poly(ADP-ribose) polymerase-1 and XRCC1/DNA ligase III in an alternative route for DNA doublestrand breaks rejoining. J. Biol. Chem. 279, 55117-55126. doi: 10.1074/jbc.M404524200

Bai, P., Canto, C., Brunyanszki, A., Huber, A., Szanto, M., Cen, Y., et al. (2011a). PARP-2 regulates SIRT1 expression and whole-body energy expenditure. Cell Metab. 13, 450-460. doi: 10.1016/j.cmet.2011.03.013

Bai, P., Canto, C., Oudart, H., Brunyanszki, A., Cen, Y., Thomas, C., et al. (2011b). PARP-1 inhibition increases mitochondrial metabolism through SIRT1 activation. Cell Metab. 13, 461-468. doi: 10.1016/j.cmet.2011.03.004

Bakkenist, C. J., and Kastan, M. B. (2003). DNA damage activates ATM through intermolecular autophosphorylation and dimer dissociation. Nature 421, 499-506. doi: 10.1038 /nature 01368

Bauer, D. E., Hatzivassiliou, G., Zhao, F., Andreadis, C., and Thompson, C. B. (2005). ATP citrate

Notably, both methylation of DSB-proximal DNA and its putative demethylation are dependent on metabolic intermediates, suggesting, that the effect of altered SAM, 2-KG, and 2-HG levels may not be limited to histone methylation, but affect the modulation of DSB repair via DNA methylation as well.

\section{PERSPECTIVE}

The repair of DNA breaks is central to cell survival, genome integrity and proper cell function. The repair machinery is, however, sensitive to perturbations in cellular homeostasis, resulting in increased DNA damage accumulation and defective genome maintenance in both aged and transformed cells. Here, we propose that metabolic changes associated with either of these processes may be a causal contributor to genomic instability due to defective chromatin-directed DSB repair (see Figure $\mathbf{1}$ and Table 1). Although the link between metabolic changes and altered chromatin organization has been established with regard to the regulation of gene expression, its link to DNA damage control remains to be identified. Based on the observations discussed here, we believe that the latter is not a matter of "if," but "how," although many questions remain to be answered. One of the most intriguing aspects of the involvement of metabolites in DSB repair is the potential to modulate repair efficiency by changing nutrient availability, cellular metabolism, and/or metabolite abundance. This may eventually be utilized to promote DNA repair and, thus, prevent damage accumulation and genomic aberrations observed with age. On the other hand, targeted metabolic changes may be employed to impair DSB repair, thus enhancing genotoxic therapy in cancer treatments. However, due to the many facets of chromatin in the regulation of DSB repair, we are still far from being able to predict how even a defined metabolic change may affect repair outcome. Investigating the interplay between metabolism, chromatin, and repair, is thus vital to further our understanding of how aging and tumorigenesis affect our genomes.

\section{ACKNOWLEDGMENTS}

We would like to thank J. Phang for critical reading of the manuscript. This work was supported by federal funds from the National Cancer Institute, National Institutes of Health and the $\mathrm{NIH}$ intramural research program.

lyase is an important component of cell growth and transformation. Oncogene 24, 6314-6322. doi: 10.1038/sj.onc. 1208773

Bekker-Jensen, S., and Mailand, N. (2010). Assembly and function of DNA double-strand break repair foci in mammalian cells. DNA Repair (Amst.) 9, 1219-1228. doi: 10.1016/j.dnarep.2010.09.010

Beneke, S. (2012). Regulation of chromatin structure by poly(ADPribosyl)ation. Front. Genet. 3:169. doi: 10.3389/fgene.2012.00169

Bitterman, K. J., Anderson, R. M., Cohen, H. Y., Latorre-Esteves, M. and Sinclair, D. A. (2002). Inhibition of silencing and accelerated aging by nicotinamide, a putative negative regulator of yeast sir2 and human SIRT1. J. Biol. Chem. 277, 4509945107. doi: 10.1074/jbc.M205670200

Black, J. C., Van Rechem, C., and Whetstine, J. R. (2012). Histone lysine methylation dynamics: establishment, regulation, and biological impact. Mol. Cell 48, 491-507. doi: 10.1016/j.molcel.2012.11.006

Botuyan, M. V., Lee, J., Ward, I. M., Kim, J. E., Thompson, J. R., Chen, J., et al. (2006). Structural basis for the methylation state-specific recognition of histone H4-K20 by 53BP1 and Crb2 in DNA repair. Cell 127, 13611373. doi: 10.1016/j.cell.2006.10.043 Bouwman, P., Aly, A., Escandell, J. M., Pieterse, M., Bartkova, J., van der Gulden, H., etal. (2010). 
53BP1 loss rescues BRCA1 deficiency and is associated with triplenegative and BRCA-mutated breast cancers. Nat. Struct. Mol. Biol. 17, 688-695. doi: 10.1038/nsmb. 1831

Braidy, N., Guillemin, G. J., Mansour, H., Chan-Ling, T., Poljak, A., and Grant, R. (2011). Age related changes in $\mathrm{NAD}^{+}$metabolism oxidative stress and Sirtl activity in Wistar rats. PLoS ONE 6:e19194. doi: 10.1371/journal.pone.0019194

Bunting, S. F., Callen, E., Wong, N., Chen, H. T., Polato, F., Gunn, A., et al. (2010). 53BP1 inhibits homologous recombination in Brcal-deficient cells by blocking resection of DNA breaks. Cell 141, 243-254. doi: 10.1016/j.cell.2010.03.012

Cedar, H., and Bergman, Y. (2009). Linking DNA methylation and histone modification: patterns and paradigms. Nat. Rev. Genet. 10, 295 304. doi: $10.1038 / n r g 2540$

Chapman, J. R., Taylor, M. R., and Boulton, S. J. (2012). Playing the end game: DNA doublestrand break repair pathway choice. Mol. Cell 47, 497-510. doi: 10.1016/j.molcel.2012.07.029

Chen, T., Hevi, S., Gay, F., Tsujimoto, N., He, T., Zhang, B., et al. (2007). Complete inactivation of DNMT1 leads to mitotic catastrophe in human cancer cells. Nat. Genet. 39, 391-396. doi: 10.1038/ng1982

Chou, D. M., Adamson, B., Dephoure, N. E., Tan, X., Nottke, A. C., Hurov, K. E., et al. (2010). A chromatin localization screen reveals poly (ADP ribose)-regulated recruitment of the repressive polycomb and NuRD complexes to sites of DNA damage. Proc. Natl. Acad. Sci. U.S.A. 107, 18475-18480. doi: 10.1073/pnas.1012946107

Ciccia, A., and Elledge, S. J. (2010). The DNA damage response: making it safe to play with knives. Mol. Cell 40, 179-204. doi: 10.1016/j.molcel.2010.09.019

Cosentino, C., and Mostoslavsky, R. (2013). Metabolism, longevity and epigenetics. Cell. Mol. Life Sci. 70, 1525-1541. doi: 10.1007/s00018013-1295-3

Cuozzo, C., Porcellini, A., Angrisano, T., Morano, A., Lee, B., Di Pardo, A., etal. (2007). DNA damage, homology-directed repair, and DNA methylation. PLoS Genet. 3:e110. doi: 10.1371/journal.pgen.0030110

Das, C., Lucia, M. S., Hansen, K. C., and Tyler, J. K. (2009). CBP/p300mediated acetylation of histone $\mathrm{H} 3$ on lysine 56. Nature 459, 113-117. doi: $10.1038 /$ nature 07861 de Capoa, A., Febbo, F. R., Giovannelli, F., Niveleau, A., Zardo, G., Marenzi, S., et al. (1999). Reduced levels of poly(ADP-ribosyl)ation result in chromatin compaction and hypermethylation as shown by cell-by-cell computer-assisted quantitative analysis. FASEB J. 13, 89-93.

Downs, J. A. (2008). Histone H3 K56 acetylation, chromatin assembly, and the DNA damage checkpoint. DNA Repair (Amst.) 7, 2020-2024. doi: 10.1016/j.dnarep.2008.08.016

Elstrom, R. L., Bauer, D. E., Buzzai, M., Karnauskas, R., Harris, M. H., Plas, D. R., et al. (2004). Akt stimulates aerobic glycolysis in cancer cells. Cancer Res. 64, 3892-3899. doi: 10.1158/0008-5472.CAN-03-2904

Feng, X., and Koh, D. W. (2013). Roles of poly(ADP-ribose) glycohydrolase in DNA damage and apoptosis. Int. Rev. Cell Mol. Biol. 304 227-281. doi: 10.1016/B978-0-12407696-9.00005-1

Feser, J., Truong, D., Das, C., Carson, J. J., Kieft, J., Harkness, T., et al. (2010). Elevated histone expression promotes life span extension. Mol. Cell 39, 724-735. doi: 10.1016/j.molcel.2010.08.015

Fnu, S., Williamson, E. A., De Haro, L. P., Brenneman, M., Wray, J., Shaheen, M., et al. (2011). Methylation of histone $\mathrm{H} 3$ lysine 36 enhances DNA repair by nonhomologous end-joining. Proc. Natl. Acad. Sci. U.S.A. 108, 540-545. doi: 10.1073/pnas. 1013571108

Forneris, F., Binda, C., Vanoni, M. A., Mattevi, A., and Battaglioli, E. (2005). Histone demethylation catalysed by LSD1 is a flavin-dependent oxidative process. FEBS Lett. 579, 2203-2207. doi: 10.1016/j.febslet.2005.03.015

Fradet-Turcotte, A., Canny, M. D., Escribano-Diaz, C., Orthwein, A., Leung, C. C., Huang, H., et al. (2013). 53BP1 is a reader of the DNA-damage-induced H2A Lys 15 ubiquitin mark. Nature 499, 50-54. doi: 10.1038/nature12318

Gil, R., Barth, S., Kanfi, Y., and Cohen, H. Y. (2013). SIRT6 exhibits nucleosome-dependent deacetylase activity. Nucleic Acids Res. doi: 10.1093/nar/gkt642 [Epub ahead of print].

Grillo, M. A., and Colombatto, S. (2008). S-adenosylmethionine and its products. Amino Acids 34, 187 193. doi: 10.1007/s00726-007-0500-9

Ha, K., Lee, G. E., Palii, S. S., Brown, K. D., Takeda, Y., Liu, K., et al. (2011). Rapid and transient recruitment of DNMT1 to DNA double-strand breaks is mediated by its interaction with multiple components of the DNA damage response machinery. Hum. Mol. Genet. 20, 126-140. doi: 10.1093/hmg/ddq451

Haigis, M. C., and Sinclair, D. A. (2010). Mammalian sirtuins: biological insights and disease relevance. Annu. Rev. Pathol. 5, 253-295. doi: 10.1146/annurev.pathol.4.110807. 092250

Haigis, M. C., and Yankner, B. A. (2010). The aging stress response. Mol. Cell 40, 333-344. doi: 10.1016/j.molcel.2010.10.002

Hansen, J. C. (2002). Conformational dynamics of the chromatin fiber in solution: determinants, mechanisms, and functions. Annu. Rev. Biophys. Biomol. Struct. 31, 361-392. doi: 10.1146/annurev.biophys.31.101101. 140858

Hsiao, K. Y., and Mizzen, C. A. (2013). Histone $\mathrm{H} 4$ deacetylation facilitates 53BP1 DNA damage signaling and double-strand break repair. $J$. Mol. Cell Biol. 5, 157-165. doi: 10.1093/jmcb/mjs066

Huyen, Y., Zgheib, O., Ditullio, R. A. Jr., Gorgoulis, V. G., Zacharatos, P., Petty, T. J., etal. (2004). Methylated lysine 79 of histone $\mathrm{H} 3 \mathrm{tar}$ gets 53BP1 to DNA double-strand breaks. Nature 432, 406-411. doi: 10.1038 /nature03114

Imai, S., Armstrong, C. M., Kaeberlein, M., and Guarente, L. (2000). Transcriptional silencing and longevity protein Sir2 is an NAD-dependent histone deacetylase. Nature 403, 795 800. doi: 10.1038/35001622

Kaidi, A., and Jackson, S. P. (2013). KAT5 tyrosine phosphorylation couples chromatin sensing to ATM signalling. Nature 498, 70-74. doi: 10.1038/nature12201

Kaidi, A., Weinert, B. T., Choudhary, C., and Jackson, S. P. (2010). Human SIRT6 promotes DNA end resection through CtIP deacetylation. Science 329, 1348-1353. doi: 10.1126/science. 1192049

Klose, R. J., Yamane, K., Bae, Y., Zhang, D., Erdjument-Bromage, H., Tempst, P., etal. (2006). The transcriptional repressor JHDM3A demethylates trimethyl histone $\mathrm{H} 3$ lysine 9 and lysine 36. Nature 442, 312-316. doi: 10.1038/nature 04853

Kouzarides, T. (2007). Chromatin modifications and their function. Cell 128, 693-705. doi: 10.1016/j.cell.2007.02.005

Kriaucionis, S., and Heintz, N. (2009). The nuclear DNA base 5hydroxymethylcytosine is present in Purkinje neurons and the brain. Science 324, 929-930. doi: 10.1126/science. 1169786
Krishnakumar, R., and Kraus, W. L. (2010). PARP-1 regulates chromatin structure and transcription through a KDM5B-dependent pathway. Mol. Cell 39, 736-749. doi: 10.1016/j.molcel.2010.08.014

Lee, G. E., Kim, J. H., Taylor, M., and Muller, M. T. (2010). DNA methyltransferase 1-associated protein (DMAP1) is a co-repressor that stimulates DNA methylation globally and locally at sites of double strand break repair. J. Biol. Chem. 285, 37630-37640. doi: 10.1074/jbc.M110.148536

Lin, S. J., Kaeberlein, M., Andalis, A. A., Sturtz, L. A., Defossez, P. A., Culotta, V. C., et al. (2002). Calorie restriction extends Saccharomyces cerevisiae lifespan by increasing respiration. Nature 418, 344-348. doi: 10.1038 /nature00829

Liu, H., Takeda, S., Kumar, R., Westergard, T. D., Brown, E. J., Pandita, T. K., et al. (2010). Phosphorylation of MLL by ATR is required for execution of mammalian S-phase checkpoint. Nature 467, 343-346. doi: 10.1038 /nature 09350

Locasale, J. W., and Cantley, L. C. (2011). Metabolic flux and the regulation of mammalian cell growth. Cell Metab. 14, 443-451. doi: 10.1016/j.cmet.2011.07.014

Lu, C., Ward, P. S., Kapoor, G. S., Rohle, D., Turcan, S., Abdel-Wahab, O., et al. (2012). IDH mutation impairs histone demethylation and results in a block to cell differentiation. Nature 483, 474-478. doi: 10.1038 /nature 10860

Luger, K., Mader, A. W., Richmond, R. K., Sargent, D. F., and Richmond, T. J. (1997). Crystal structure of the nucleosome core particle at $2.8 \AA$ resolution. Nature 389, 251-260. doi: $10.1038 / 38444$

Lukas, J., Lukas, C., and Bartek, J. (2011). More than just a focus: the chromatin response to DNA damage and its role in genome integrity maintenance. Nat. Cell Biol. 13, 1161-1169. doi: 10.1038/ncb2344

Mallette, F. A., Mattiroli, F., Cui, G., Young, L. C., Hendzel, M. J., Mer, G., et al. (2012). RNF8and RNF168-dependent degradation of KDM4A/JMJD2A triggers 53BP1 recruitment to DNA damage sites. EMBO J. 31, 1865-1878. doi: 10.1038/emboj. 2012.47

Mao, Z., Hine, C., Tian, X., Van Meter, M., Au, M., Vaidya, A., et al. (2011). SIRT6 promotes DNA repair under stress by activating PARP1. Science 332, 1443-1446. doi: 10.1126/science. 1202723 
Mardis, E. R., Ding, L., Dooling, D. J., Larson, D. E., McLellan, M. D., Chen, K., et al. (2009). Recurring mutations found by sequencing an acute myeloid leukemia genome. $N$. Engl. J. Med. 361, 1058-1066. doi: 10.1056/NEJMoa0903840

Martinez-Zamudio, R., and $\mathrm{Ha}, \mathrm{H}$. C. (2012). Histone ADP-ribosylation facilitates gene transcription by directly remodeling nucleosomes. Mol. Cell. Biol. 32, 2490-2502. doi: 10.1128/MCB.06667-11

Massudi, H., Grant, R., Braidy, N., Guest, J., Farnsworth, B., and Guillemin, G. J. (2012). Ageassociated changes in oxidative stress and $\mathrm{NAD}^{+}$metabolism in human tissue. PLoS ONE 7:e42357. doi: 10.1371/journal.pone.0042357

Menissier de Murcia, J., Ricoul, M., Tartier, L., Niedergang, C., Huber, A., Dantzer, F., et al. (2003). Functional interaction between PARP-1 and PARP-2 in chromosome stability and embryonic development in mouse. EMBO J. 22, 2255-2263. doi: 10.1093/emboj/cdg206

Messner, S., Altmeyer, M., Zhao, H., Pozivil, A., Roschitzki, B., Gehrig, P., et al. (2010). PARP1 ADP-ribosylates lysine residues of the core histone tails. Nucleic Acids Res. 38, 63506362. doi: 10.1093/nar/gkq463

Michishita, E., McCord, R. A., Berber, E., Kioi, M., Padilla-Nash, H., Damian, M., et al. (2008). SIRT6 is a histone $\mathrm{H} 3$ lysine 9 deacetylase that modulates telomeric chromatin. Nature 452, 492-496. doi: 10.1038 /nature06736

Michishita, E., McCord, R. A., Boxer, L. D., Barber, M. F., Hong, T., Gozani, O., et al. (2009). Cell cycledependent deacetylation of telomeric histone $\mathrm{H} 3$ lysine K56 by human SIRT6. Cell Cycle 8, 2664-2666. doi: 10.4161/cc.8.16.9367

Murr, R., Loizou, J. I., Yang, Y. G., Cuenin, C., Li, H., Wang, Z. Q., et al. (2006). Histone acetylation by TrrapTip60 modulates loading of repair proteins and repair of DNA doublestrand breaks. Nat. Cell Biol. 8, 91-99. doi: $10.1038 /$ ncb 1343

Nottke, A. C., Beese-Sims, S. E., Pantalena, L. F., Reinke, V., Shi, Y., and Colaiacovo, M. P. (2011). SPR-5 is a histone H3K4 demethylase with a role in meiotic doublestrand break repair. Proc. Natl. Acad. Sci. U.S.A. 108, 12805-12810. doi: $10.1073 /$ pnas. 1102298108

Oberdoerffer, P., Michan, S., McVay, M., Mostoslavsky, R., Vann, J., Park, S. K., et al. (2008). SIRT1 redistribution on chromatin promotes genomic stability but alters gene expression during aging. Cell 135, 907-918. doi: 10.1016/j.cell.2008.10.025

Ogiwara, H., Ui, A., Otsuka, A., Satoh H., Yokomi, I., Nakajima, S., et al. (2011). Histone acetylation by CBP and p300 at double-strand break sites facilitates SWI/SNF chromatin remodeling and the recruitment of non-homologous end joining factors. Oncogene 30, 2135-2146. doi: 10.1038/onc. 2010.592

O'Sullivan, R. J., Kubicek, S., Schreiber, S. L., and Karlseder, J. (2010). Reduced histone biosynthesis and chromatin changes arising from a damage signal at telomeres. Nat. Struct. Mol. Biol. 17, 1218-1225. doi: 10.1038/nsmb.1897

Palacios, J. A., Herranz, D., De Bonis, M. L., Velasco, S., Serrano, M., and Blasco, M. A. (2010). SIRT1 contributes to telomere maintenance and augments global homologous recombination. J. Cell Biol. 191, 1299-1313. doi: $10.1083 /$ jcb. 201005160

Parsons, D. W., Jones, S., Zhang, X., Lin, J. C., Leary, R. J., Angenendt, P., et al. (2008). An integrated genomic analysis of human glioblastoma multiforme. Science 321 , 1807-1812. doi: 10.1126/science.11 64382

Pei, H., Zhang, L., Luo, K., Qin, Y., Chesi, M., Fei, F., et al. (2011). MMSET regulates histone $\mathrm{H} 4 \mathrm{~K} 20$ methylation and 53BP1 accumulation at DNA damage sites. Nature 470, 124-128. doi: 10.1038/nature09658

Penicud, K., and Behrens, A. (2013). DMAP1 is an essential regulator of ATM activity and function. Oncogene doi: 10.1038/onc.2012.597 [Epub ahead of print].

Polo, S. E., and Jackson, S. P. (2011). Dynamics of DNA damage response proteins at DNA breaks: a focus on protein modifications. Genes Dev. 25, 409-433. doi: 10.1101/gad.2021311

Qian, M. X., Pang, Y., Liu, C. H., Haratake, K., Du, B. Y., Ji, D. Y., et al. (2013). Acetylationmediated proteasomal degradation of core histones during DNA repair and spermatogenesis. Cell 153, 10121024. doi: 10.1016/j.cell.2013.04 032

Reale, A., Matteis, G. D., Galleazzi, G., Zampieri, M., and Caiafa, P. (2005). Modulation of DNMT1 activity by ADP-ribose polymers. Oncogene 24, 13-19. doi: 10.1038/sj.onc. 1208005

Sahm, F., Oezen, I., Opitz, C. A., Radlwimmer, B., von Deimling, A., Ahrendt, T., et al. (2013). The endogenous tryptophan metabolite and $\mathrm{NAD}^{+}$precursor quinolinic acid confers resistance of gliomas to oxidative stress. Cancer Res.
73, 3225-3234. doi: 10.1158/00085472.CAN-12-3831

Schreiber, V., Dantzer, F., Ame, J. C., and de Murcia, G. (2006). Poly(ADPribose): novel functions for an old molecule. Nat. Rev. Mol. Cell Biol. 7, 517-528. doi: 10.1038/nrm 1963

Shi, L., and Oberdoerffer, P. (2012). Chromatin dynamics in DNA double-strand break repair. Biochim. Biophys. Acta 1819, 811-819. doi: 10.1016/j.bbagrm.2012.01.002

Shi, Y., Lan, F., Matson, C., Mulligan, P., Whetstine, J. R., Cole, P. A., et al. (2004). Histone demethylation mediated by the nuclear amine oxidase homolog LSD1. Cell 119, 941-953. doi: 10.1016/j.cell.2004.12.012

Smeenk, G., and van Attikum, H. (2013). The chromatin response to DNA breaks: leaving a mark on genome integrity. Annu. Rev. Biochem. 82, 55-80. doi 10.1146/annurev-biochem-061809174504

Smeenk, G., Wiegant, W. W., Marteijn, J. A., Luijsterburg, M. S., Sroczynski, N., Costelloe, T., et al. (2013). Poly(ADP-ribosyl)ation links the chromatin remodeler SMARCA5/SNF2H to RNF168dependent DNA damage signaling. J. Cell Sci. 126, 889-903. doi: 10.1242/jcs. 109413

Soria, G., Polo, S. E., and Almouzni, G. (2012). Prime, repair, restore: the active role of chromatin in the DNA damage response. Mol. Cell 46, 722-734. doi: 10.1016/j.molcel.2012.06.002

Sun, Y., Jiang, X., Chen, S., Fernandes, N., and Price, B. D. (2005). A role for the Tip60 histone acetyltransferase in the acetylation and activation of ATM. Proc. Natl. Acad. Sci. U.S.A. 102, 13182-13187. doi: 10.1073/pnas.0504211102

Sun, Y., Jiang, X., Xu, Y., Ayrapetov, M. K., Moreau, L. A., Whetstine, J. R., et al. (2009). Histone H3 methylation links DNA damage detection to activation of the tumour suppressor Tip60. Nat. Cell Biol. 11, 1376-1382. doi: $10.1038 /$ ncb1982

Sun, Y., Xu, Y., Roy, K., and Price, B. D. (2007). DNA damage-induced acetylation of lysine 3016 of ATM activates ATM kinase activity. Mol. Cell. Biol. 27, 8502-8509. doi: 10.1128/MCB.01382-07

Tahiliani, M., Koh, K. P., Shen, Y., Pastor, W. A., Bandukwala, H., Brudno, Y., et al. (2009). Conversion of 5-methylcytosine to 5-hydroxymethylcytosine in mammalian DNA by MLL partner TET1. Science 324, 930-935. doi: 10.1126/science. 1170116
Tamburini, B. A., and Tyler, J. K. (2005). Localized histone acetylation and deacetylation triggered by the homologous recombination pathway of double-strand DNA repair. Mol. Cell. Biol. 25, 4903-4913. doi: 10.1128/MCB.25.12.4903-4913.2005

Tang, J., Cho, N. W., Cui, G., Manion, E. M., Shanbhag, N. M., Botuyan, M. V., et al. (2013). Acetylation limits 53BP1 association with damaged chromatin to promote homologous recombination. Nat. Struct. Mol. Biol. 20, 317-325. doi: 10.1038/nsmb.2499

Tjeertes, J. V., Miller, K. M., and Jackson, S. P. (2009). Screen for DNA-damageresponsive histone modifications identifies $\mathrm{H} 3 \mathrm{~K} 9 \mathrm{Ac}$ and $\mathrm{H} 3 \mathrm{~K} 56 \mathrm{Ac}$ in human cells. EMBO J. 28, 1878-1889. doi: 10.1038/emboj.2009.119

Toiber, D., Erdel, F., Bouazoune, K., Silberman, D. M., Zhong, L., Mulligan, P., et al. (2013). SIRT6 recruits SNF2H to DNA break sites, preventing genomic instability through chromatin remodeling. Mol. Cell 51, 454-468. doi: 10.1016/j.molcel.2013.06.018

Tong, W. M., Yang, Y. G., Cao, W. H., Galendo, D., Frappart, L., Shen, Y., et al. (2007). Poly(ADP-ribose) polymerase-1 plays a role in suppressing mammary tumourigenesis in mice. Oncogene 26, 3857-3867. doi: 10.1038/sj.onc.1210156

Tulin, A., and Spradling, A. (2003). Chromatin loosening by poly(ADP)-ribose polymerase (PARP) at Drosophila puff loci. Science 299, 560-562. doi: 10.1126/science. 1078764

van Attikum, H., and Gasser, S. M. (2009). Crosstalk between histone modifications during the DNA damage response. Trends Cell Biol. 19, 207-217. doi: 10.1016/j.tcb.2009.03.001

Vaquero, A., Scher, M., ErdjumentBromage, H., Tempst, P., Serrano, L., and Reinberg, D. (2007). SIRT1 regulates the histone methyl-transferase SUV39H1 during heterochromatin formation. Nature 450, 440-444. doi: 10.1038 /nature 06268

Vaquero, A., Scher, M., Lee, D., Erdjument-Bromage, H., Tempst, P., and Reinberg, D. (2004). Human SirT1 interacts with histone $\mathrm{H} 1$ and promotes formation of facultative heterochromatin. Mol. Cell 16, 93-105. doi: 10.1016/j.molcel.2004.08.031

Vousden, K. H., and Ryan, K. M. (2009). p53 and metabolism. Nat. Rev. Cancer 9, 691-700. doi: 10.1038/nrc2715

Wakeman, T. P., Wang, Q., Feng, J., and Wang, X. F. (2012). Bat3 facilitates H3K79 dimethylation by 
DOT1L and promotes DNA damageinduced 53BP1 foci at G1/G2 cell-cycle phases. EMBO J. 31, 2169-2181. doi: 10.1038/emboj. 2012.50

Warburg, O. (1956). On the origin of cancer cells. Science 123, 309314. doi: 10.1126/science.123.3191. 309

Ward, P. S., Patel, J., Wise, D. R., AbdelWahab, O., Bennett, B. D., Coller H. A., et al. (2010). The common feature of leukemia-associated IDH1 and IDH2 mutations is a neomorphic enzyme activity converting alphaketoglutarate to 2-hydroxyglutarate. Cancer Cell 17, 225-234. doi: 10.1016/j.ccr.2010.01.020

Ward, P. S., and Thompson, C. B. (2012). Metabolic reprogramming: a cancer hallmark even Warburg did not anticipate. Cancer Cell 21, 297-308. doi: 10.1016/j.ccr.2012.02. 014

Wellen, K. E., Hatzivassiliou, G., Sachdeva, U. M., Bui, T. V., Cross, J. R., and Thompson, C. B. (2009). ATP-citrate lyase links cellular metabolism to histone acetylation. Science 324, 1076-1080. doi: 10.1126/science.1164097

Whetstine, J. R., Nottke, A., Lan, F., Huarte, M., Smolikov, S., Chen, Z., et al. (2006). Reversal of histone lysine trimethylation by the
JMJD2 family of histone demethylases. Cell 125, 467-481. doi: 10.1016/j.cell.2006.03.028

Xhemalce, B., and Kouzarides, T. (2010). A chromodomain switch mediated by histone H3 Lys 4 acetylation regulates heterochromatin assembly. Genes Dev. 24, 647-652. doi: 10.1101/gad.1881710

Xu, W., Yang, H., Liu, Y., Yang, Y., Wang, P., Kim, S. H., et al. (2011). Oncometabolite 2-hydroxyglutarate is a competitive inhibitor of alpha-ketoglutarate-dependent dioxygenases. Cancer Cell 19, 17-30. doi: 10.1016/j.ccr.2010.12.014

Xu, Y., Ayrapetov, M. K., Xu, C., GursoyYuzugullu, O., $\mathrm{Hu}, \mathrm{Y}$. , and Price, B. D. (2012). Histone H2A.Z controls a critical chromatin remodeling step required for DNA double-strand break repair. Mol. Cell 48, 723-733. doi: 10.1016/j.molcel.2012.09.026

Yang, B., Zwaans, B. M., Eckersdorff, M., and Lombard, D. B. (2009). The sirtuin SIRT6 deacetylates H3 K56Ac in vivo to promote genomic stability. Cell Cycle 8, 2662-2663. doi: 10.4161/cc.8.16.9329

Yang, H., Yang, T., Baur, J. A., Perez, E., Matsui, T., Carmona, J. J., et al. (2007). Nutrient-sensitive mitochondrial $\mathrm{NAD}^{+}$levels dictate cell survival. Cell 130, 1095-1107. doi: 10.1016/j.cell.2007.07.035
Yang, H., Ye, D., Guan, K. L., and Xiong, Y. (2012). IDH1 and IDH2 mutations in tumorigenesis: mechanistic insights and clinical perspectives. Clin. Cancer Res. 18, 5562-5571. doi: 10.1158/1078-0432.CCR-12-1773

Yang, X., Li, L., Liang, J., Shi, L., Yang, J., Yi, X., Zhang, D., etal. (2013). Histone acetyltransferase 1 promotes homologous recombination in DNA repair by facilitating histone turnover. J. Biol. Chem. 288, 18271-18282. doi: 10.1074/jbc.M113.473199

Yelamos, J., Farres, J., Llacuna, L., Ampurdanes, C., and MartinCaballero, J. (2011). PARP-1 and PARP-2: new players in tumour development. Am. J. Cancer Res. 1, 328-346.

Young, L. C., McDonald, D. C., and Hendzel, M. J. (2013). Kdm4b histone demethylase is a DNA damage response protein and confers a survival advantage following gamma-irradiation. J. Biol. Chem. 288, 21376-21388. doi: 10.1074/jbc.M113.491514

Yuan, H. X., Xiong, Y., and Guan, K. L. (2013). Nutrient sensing, metabolism, and cell growth control. Mol. Cell 49, 379-387. doi: 10.1016/j.molcel.2013.01.019

Yun, J., Johnson, J. L., Hanigan, C. L., and Locasale, J. W. (2012).
Interactions between epigenetics and metabolism in cancers. Front. Oncol. 2:163. doi: $10.3389 /$ fonc. 2012.00163

Conflict of Interest Statement: The authors declare that the research was conducted in the absence of any commercial or financial relationships that could be construed as a potential conflict of interest.

Received: 02 July 2013; accepted: 27 August 2013; published online: 17 September 2013.

Citation: Liu J, Kim J and Oberdoerffer $P$ (2013) Metabolic modulation of chromatin: implications for DNA repair and genomic integrity. Front. Genet. 4:182. doi: 10.3389/fgene.2013.00182

This article was submitted to Genetics of Aging, a section of the journal Frontiers in Genetics.

Copyright () 2013 Liu, Kim and Oberdoerffer. This is an open-access article distributed under the terms of the Creative Commons Attribution License (CC BY). The use, distribution or reproduction in other forums is permitted, provided the original author(s) or licensor are credited and that the original publication in this journal is cited, in accordance with accepted academic practice. No use, distribution or reproduction is permitted which does not comply with these terms. 